\title{
For veterans with mild traumatic brain injury, improved posttraumatic stress disorder severity and sleep correlated with symptomatic improvement
}

\author{
Robert L. Ruff, MD, PhD; ${ }^{1-3^{*}}$ Ronald G. Riechers II, MD; ${ }^{1-3}$ Xiao-Feng Wang, PhD; ${ }^{4}$ Traci Piero, NP-C, \\ MSN; ${ }^{2}$ Suzanne S. Ruff, PhD ${ }^{3,5}$ \\ ${ }^{1}$ Neurology Service, Louis Stokes Cleveland Department of Veterans Affairs Medical Center (CVAMC), Cleveland, \\ $\mathrm{OH} ;{ }^{2}$ Department of Neurology, Case Western Reserve University, Cleveland, $\mathrm{OH} ;{ }^{3}$ Polytrauma System of Care, \\ CVAMC, Cleveland, $\mathrm{OH} ;{ }^{4}$ Department of Quantitative Health Sciences, The Cleveland Clinic, Cleveland, $\mathrm{OH}$; \\ ${ }^{5}$ Psychology Service, CVAMC, Cleveland, $\mathrm{OH}$
}

\begin{abstract}
This was an observational study of a cohort of 63 Operation Iraqi Freedom/Operation Enduring Freedom veterans with mild traumatic brain injury (mTBI) associated with an explosion. They had headaches, residual neurological deficits (NDs) on neurological examination, and posttraumatic stress disorder (PTSD) and were seen on average 2.5 years after their last mTBI. We treated them with sleep hygiene counseling and oral prazosin. We monitored headache severity, daytime sleepiness using the Epworth Sleepiness Scale, cognitive performance using the Montreal Cognitive Assessment test, and the presence of NDs. We quantitatively measured olfaction and assessed PTSD severity using the PTSD Checklist-Military Version. Nine weeks after starting sleep counseling and bedtime prazosin, the veterans' headache severity decreased, cognitive function as assayed with a brief screening tool improved, and daytime sleepiness diminished. Six months after completing treatment, the veterans demonstrated additional improvement in headache severity and daytime sleepiness and their improvements in cognitive function persisted. There were no changes in the prevalence of NDs or olfaction scores. Clinical improvements correlated with reduced PTSD severity and daytime sleepiness. The data suggested that reduced clinical manifestations following mTBI correlated with PTSD severity and improvement in sleep, but not the presence of NDs or olfaction impairment.
\end{abstract}

Key words: combat, concussion, headache, mild traumatic brain injury, OIF/OEF, olfaction, pain, prazosin, PTSD, sleep.

\section{INTRODUCTION}

For U.S. troops, combat mild traumatic brain injury (mTBI) associated with deployments to Iraq or Afghanistan as part of Operation Iraqi Freedom (OIF)/Operation Enduring Freedom (OEF) is often associated with posttraumatic stress disorder (PTSD); impaired sleep; and pain, particularly headaches [1-3]. These issues may persist for several years after their episodes of combat-associated head trauma

\footnotetext{
Abbreviations: AOC $=$ alteration of consciousness, $\mathrm{CI}=$ confidence interval, CVAMC = (Louis Stokes) Cleveland Department of Veterans Affairs Medical Center, ESS = Epworth Sleepiness Scale, LOC = loss of consciousness, MOCA = Montreal Cognitive Assessment, mTBI = mild traumatic brain injury, ND = neurological deficit, NSAID = nonsteroidal antiinflammatory drug, OEF = Operation Enduring Freedom, OIF = Operation Iraqi Freedom, PCL-M = Posttraumatic Stress Disorder Checklist-Military Version, PTA = posttraumatic amnesia, PTSD = posttraumatic stress disorder, SE = standard error of the mean, TBI = traumatic brain injury, VHIP = Vietnam Head Injury Program.

*Address all correspondence to Robert L. Ruff, MD, PhD; Neurology Service, 127(W), Louis Stokes Cleveland Department of Veterans Affairs Medical Center, 10701 East Blvd, Cleveland, OH 44106; 216-791-3800, ext 5230; fax: 216-707-6401. Email: robert.ruff1@va.gov http://dx.doi.org/10.1682/JRRD.2011.12.0251
} 
[4-7]. In both Vietnam-era veterans [8] and military personnel deployed in OIF/OEF [9], prazosin improved sleep by reducing nightmares. We found in an observational study that a treatment protocol using prazosin and sleep hygiene counseling reduced the frequency and severity of headaches in a group of U.S. OIF/OEF veterans who had physician-confirmed episodes of mTBI associated with loss of consciousness (LOC) due to explosions in combat [10]. All the veterans had headaches, which they stated developed following mTBI. They also had PTSD or neurological deficits (NDs). The question addressed here is, Are reductions in postconcussive symptoms, such as headaches and impaired cognitive function, associated with reduction of PTSD severity, resolution of NDs, or both? To address this question, we evaluated a subset of 63 veterans from the observational study who each had the triad of headache, PTSD, and an ND that included impaired olfaction to determine whether improvement in headaches and cognitive function were associated with reductions in PTSD severity, impaired olfaction severity, or prevalence of an ND. We collected data while providing treatment. Therefore, data collection was not blinded.

\section{METHODS}

\section{Criteria for mTBI and Combat mTBI}

The criteria for mTBI, which were consistent with other established criteria, included an episode of traumatic brain injury (TBI) with duration of any alteration of consciousness (AOC) following the TBI $<24 \mathrm{~h}$, LOC $<30$ min, or posttraumatic amnesia (PTA) $<24$ h [11]. AOC episodes were periods when the veteran was dazed or confused. PTA episodes were times when the veteran could not remember what happened or had memory gaps for events before or after an episode of head trauma. LOC was a time interval when someone at the trauma scene observed the veteran to be unresponsive or the veteran did not move when prompted or prodded. When no observers were present, a veteran could indicate an episode of LOC by stating that he or she clearly "woke up" or aroused after head trauma. We focused on episodes of mTBI with LOC because TBI depended on subjects recalling an event. We believed that it might be difficult in a combat setting to distinguish AOC from conflictinduced changes in arousal or emotion.

Each subject in this study had at least one episode of mTBI with LOC in combat. We defined combat mTBI as
(1) occurring during enemy engagement or (2) caused by an explosion from an enemy explosive device (e.g., bomb, improvised explosive device, rocket-propelled grenade, or mortar/artillery shell).

\section{Subject Selection}

As previously stated [10], this was an observational study of a cohort of U.S. OIF/OEF veterans with combat mTBI associated with an explosion. This study was a Neurology Service Quality Assurance Monitor of the evaluation and treatment of OIF/OEF veterans with mTBI. The study was conducted at the Louis Stokes Cleveland Department of Veterans Affairs Medical Center (CVAMC), which is a regional Polytrauma Center that addresses the needs of OIF/OEF veterans for most of the state of Ohio.

Figure 1 shows how we selected the cohort of 63 veterans in this study. During a 24 mo interval between 2006 and 2008, 2,091 veterans of OIF/OEF were screened with the Department of Veterans Affairs initiallevel four-question TBI screening instrument, which has been validated [12]. This was followed by a second-level TBI screening consisting of questions assessing for postconcussion symptoms and a structured neurological examination. The individuals who were identified on the second-level TBI screening were invited to undergo additional assessment that consisted of an interview, a detailed structured neurological examination, and a cognitive assessment test (described subsequently). We used open-ended questions to induce the veteran to describe what happened during each episode of possible TBI. The study group consisted of 63 veterans who had one or more episodes of clinician-confirmed mTBI with LOC that occurred in a combat setting. In addition, each veteran in the study group had one or more NDs, including impaired olfaction, and PTSD. The subject population in our prior study of the effects of sleep hygiene counseling and prazosin treatment was 74 veterans, all of whom had headaches and an ND or abnormality on neuropsychological testing [10]. The 63 subjects in this study were a subset of those 74 veterans, with the additional requirements that each veteran in this study had PTSD and an ND.

\section{Subject Evaluation}

We previously described the neurological examination [13]. It included 50 scored elements (Appendix, available online only). The neurological examination included a 12-item quantitative olfactory test (Brief Smell 


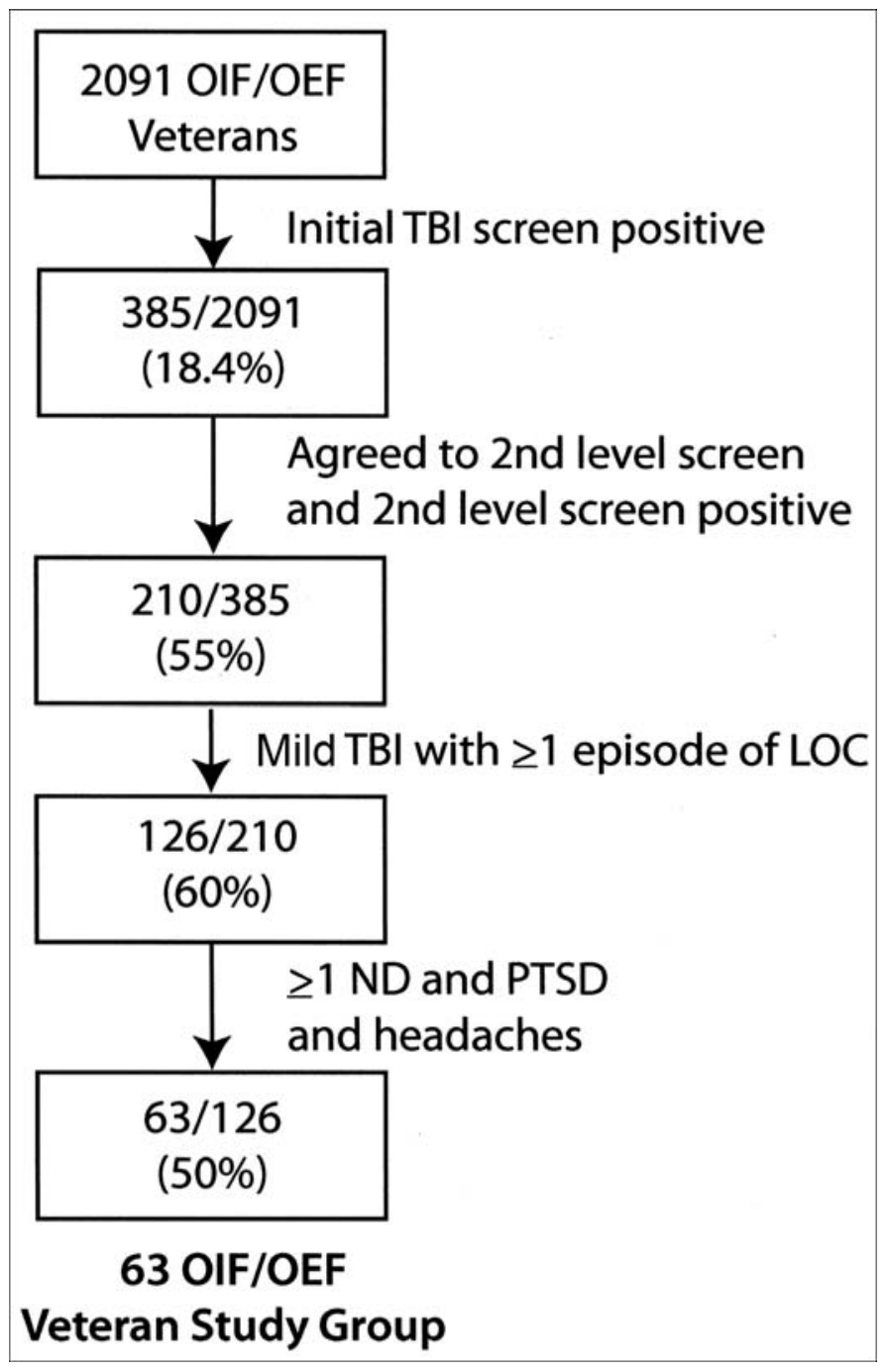

Figure 1.

Sequential screening of subjects from initial pool of 2,091 Operation Iraqi Freedom/Operation Enduring Freedom (OIF/OEF) veterans to final study group of 63 veterans who had experienced at least one episode of combat mild traumatic brain injury (TBI) associated with loss of consciousness (LOC), neurological deficit (ND), and posttraumatic stress disorder (PTSD).

Identification Test, Sensonics; Haddon Heights, New Jersey, www.sensonics.com) [14]. Each odor was evoked in a standardized manner. The veteran identified the scent from a list of choices. Olfactory test scores had normal values that were adjusted for age and sex [15]. Normal olfaction test results scores were $\geq 7 / 12$ for veterans younger than $55 \mathrm{yr}$ and $\geq 5 / 12$ for veterans $55 \mathrm{yr}$ and older. The veterans provided no histories of impaired olfaction before OIF/OEF deployments. The Montreal Cognitive
Assessment (MOCA) measured cognitive function [1617]. It had a range of $0-30$ points. The first author (RLR) administered the MOCA after he obtained the TBI history. Several studies used the MOCA to obtain serial assessments of cognitive function [16-17].

We previously described the division of headache episodes into three categories: (1) muscle tension headaches, (2) migraine, and (3) mixed tension and migraine headaches $[10,13,18]$. Veterans indicated that the headaches developed during deployment following an episode of mTBI. We did not consider headaches that manifested after returning from deployment. As previously stated, the highest pain level experienced during a headache was scored on an 11-point numerical scale $(0-10)[10,13]$. To standardize the duration of time for determining headache frequency, we considered a month to be 4 wk or $28 \mathrm{~d}$. Veterans kept headache diaries and recorded the number of headaches in each $28 \mathrm{~d}$ period of the study. The headache frequency for baseline, $9 \mathrm{wk}$, and the end of the study was the number of headaches a veteran experienced in the prior month. The International Headache Society has defined chronic daily headaches as headaches occurring 15 or more times per month [18]. If a veteran reported 15 or more headaches per month, we recorded the headache frequency as 15 per month. Setting the maximum headache frequency at 15 per month allowed us to normalize the headache frequency.

As previously stated [10,13], every study subject was assessed for PTSD. The initial screen had four questions about PTSD symptoms. If a veteran acknowledged any three items, the screen was positive. The veteran was referred for further evaluation by a mental health professional qualified to diagnose PTSD. The PTSD assessment included the National Center for PTSD's 17-item checklist for symptoms of military PTSD (PTSD ChecklistMilitary Version [PCL-M]) [19]. PTSD diagnosis satisfied the American Psychiatric Association's Diagnostic and Statistical Manual of Mental Disorders, 4th edition, criteria of at least one intrusion item (questions $1-5$ of the PCL-M), three avoidance items (questions 6-12), and two hyperarousal symptoms (questions 13-17) [19]. Symptoms rated as "moderately severe" or "more severe" (responses 3-5) were considered to be present. Additionally, the subject needed to have a substantial distress level, which was indicated by a PCL-M score $>50$ [19].

PTSD was treated by mental health professionals. Pharmacological treatment for PTSD consisted of citalopram (51 veterans) or quetiepine (12 veterans). Doses of 
medication for PTSD did not change during the $9 \mathrm{wk}$ study period. The most common medication for PTSD and dosing was citalopram at $20 \mathrm{mg}$ per day (47 veterans). After the 9 wk study period ended, the mental health professionals changed dosing of PTSD medication for 18 veterans.

We interviewed subjects about their use of pain medications. Table 1 shows the baseline usage frequencies of opioid medications (opioid medication alone or combined with acetaminophen), and nonsteroidal antiinflammatory drugs (NSAIDs). We advised subjects to follow the same medication schedule during the initial 9 wk study period. During the 6 mo period after the end of the study period, we tapered subjects off opioid medications and provided specific medications for migraine headaches. The specific migraine headache treatment included using a triptan at the start of a headache. During the study period, rizatriptan was the triptan most often provided by the CVAMC. If the subject had more than two migraine headaches per month, we counseled him or her about different types of

Table 1.

Demographic features of study group of 63 Operation Iraqi Freedom/ Operation Enduring Freedom (OIF/OEF) veterans who sustained mild traumatic brain injury (TBI) in combat in association with explosion. Each veteran had 1 or more episodes of loss of consciousness, neurological deficit (ND), and posttraumatic stress disorder (PTSD).

\begin{tabular}{lc}
\multicolumn{1}{c}{ Demographic } & $\begin{array}{c}\text { Veterans with } \\
\text { Combat Mild } \\
\text { TBI, ND, \& } \\
\text { PTSD }\end{array}$ \\
\hline Age at Evaluation (yr) & \\
Mean \pm SE & $29.50 \pm 0.92$ \\
Range & $20-62$ \\
Women, $n$ (\%) & $6(9.52)$ \\
High School Graduate, $n$ (\%) & $63(100)$ \\
College Graduate, $n$ (\%) & $6(9.52)$ \\
OIF/OEF Deployment Duration (wk) & \\
Mean \pm SE & $83.40 \pm 3.86$ \\
Range & $52-184$ \\
Interval from Last TBI to Assessment (mo) & \\
Mean \pm SE & $30.80 \pm 1.47$ \\
Median & 30.5 \\
Range & $11-54$ \\
Baseline Headache Medications, $n$ (\%) & \\
Opioid ( \pm Acetaminophen) & $26(41.3)$ \\
NSAID & $46(73.0)$ \\
Opioid and/or NSAID & $61(96.8)$ \\
\hline NSAID = nonsteroidal antiinflammatory drug, SE = standard error of the mean. \\
\hline \hline
\end{tabular}

medications to prevent headaches. The headache preventatives included (1) beta-adrenergic blocking agents (propranolol and metopranol), (2) topirimate, (3) valproate, and (4) tricyclic antidepressant agents. The veteran chose the migraine prevention agent. If the prevention agent chosen did not reduce headache intensity or frequency after 3 mo of treatment, the subject was encouraged to select another migraine prevention agent and that agent was introduced while the unsuccessful prevention agent was discontinued.

We used the Epworth Sleepiness Scale (ESS) to assess daytime sleepiness as a measure of the effectiveness of nocturnal sleep [20]. ESS scores range from 0 to 24. The ESS has been validated and has high sensitivity and specificity for impaired sleep [20].

\section{Sleep Hygiene Counseling and Prazosin Intervention}

As previously stated [10], we treated all the subjects in the same manner with sleep hygiene counseling and prazosin. Prazosin successfully improved sleep in Vietnam veterans [8] and soldiers deployed in OIF [9]. Prazosin acts by reducing alpha adrenergic activity in the brain [21]. The clinical benefit of prazosin treatment is to reduce the severity and frequency of nightmares associated with PTSD [22]. We previously reported the dosing schedule for prazosin and the features of sleep hygiene counseling [10]. Prazosin dosing began at $1 \mathrm{mg}$ by mouth at bedtime. The prazosin dose increased weekly to $2,4,5$, and $7 \mathrm{mg}$ at bedtime. The targeted treatment dose of prazosin was $7 \mathrm{mg}$ at bedtime, which was reached at $5 \mathrm{wk}$. We increased the prazosin dose slowly to avoid the unwanted side effect of postural hypotension [21]. Hence, the 9 wk analysis was done 1 mo after completion of the prazosin dosing introduction period.

We monitored veterans for the following potential adverse reactions to prazosin: abnormalities in liver function tests, reduction in white blood cell counts, change in bowel habits, light headedness, excessive daytime somnolence, and development of a skin rash or pruritis. We monitored the following liver function tests at baseline, at the end of the $9 \mathrm{wk}$ intervention period, and at the end of the 6 mo follow-up period: alkaline phosphatase, aspartate aminotransferase (AST or SGOT [aspartate aminotransferase]), alanine aminotransferase (ALT or SGPT [alanine aminotransferase]), total bilirubin, direct bilirubin, total serum protein, and serum albumin. 


\section{Statistical Methods}

The independent variables were the duration of treatment with prazosin and sleep hygiene counseling and deployment duration. The dependent variables were (1) olfaction testing score, (2) PCL-M score, (3) number of headaches per month, (4) severity of headache pain, (5) MOCA score, and (6) ESS score.

We normalized the data for Figure 2 in the following ways. For headache frequency, headache pain intensity, ESS scores, MOCA scores, and olfaction scores, we divided the mean data values by the maximum value of the data range and multiplied by 100 . For example, the mean value of the headache frequency was divided by 15 and the headache pain was divided by 10 ; both values were then multiplied by 100 to determine the normalized values for headache frequency and headache pain. To normalize the PCL-M values, we subtracted 17 from the mean value, divided the resulting value by 68 , and then multiplied by 100 . Thus, a PCL-M score of 85 would have a normalized value of 100 and a PCL-M score of 17 would have a normalized value of 0 .

For the analysis shown in Figure 2, we evaluated the changes of the six measures (headache pain and frequency, ESS, MOCA, PCL-M, and olfaction test) at three times: baseline, $9 \mathrm{wk}$ and, finally, 6 mo after the $9 \mathrm{wk}$

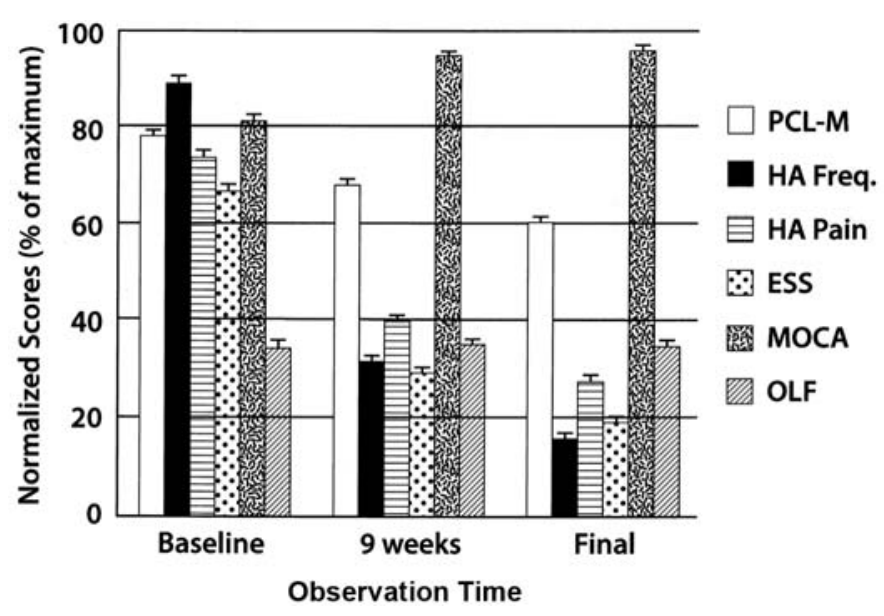

Figure 2.

Normalized values of variables at baseline, $9 \mathrm{wk}$ after initiation of sleep hygiene counseling and prazosin treatment, and 6 mo after completion of 9 wk initiation period (final). ESS = Epworth Sleepiness Scale, Freq. = frequency, $\mathrm{HA}=$ headache, $\mathrm{MOCA}=$ Montreal Cognitive Assessment, OLF = olfaction, PCL-M = Posttraumatic Stress Disorder Checklist-Military Version. measures. We used linear mixed-effect models that were fitted to each response with time as a covariate. We plotted box plots of the data and reported the normalized mean and standard error of the mean (SE) in Figure 2. Analysis of variance tests were performed to examine whether there were changes among the three time points (baseline, $9 \mathrm{wk}$, final). Pairwise comparisons were also performed over the three time groups. The Tukey method was used to adjust the multiple testing issues in the pairwise comparisons [23-25].

We performed correlation analyses based on four types of statistical methods: (1) Pearson product-moment correlation, (2) Spearman rank-order correlation, (3) Kendall tau-b correlation coefficient, and (4) Hoeffding dependence coefficient. All four types of correlation coefficients have values between -1 and 1 [26-27]. For each correlation, we performed statistical testing to determine whether the correlation coefficients were equal to 0 . The $p$-values are reported. Pearson product-moment correlation has an assumption of normality of data. The data satisfied normality requirements. The other correlation analysis methods were nonparametric correlations. The following describes the correlation analysis methods. The Pearson productmoment correlation is a parametric measure of association for two variables. It measures both the strength and the direction of a linear relationship. If one variable $x$ is an exact linear function of another variable $y$, a positive relationship exists if the correlation is 1 and a negative relationship exists if the correlation is -1 . If there is no linear predictability between the two variables, the correlation is 0 . If two variables have normal distributions with a correlation 0 , the two variables are independent. Spearman rankorder correlation is a nonparametric measure of association based on the ranks of the data values. The Spearman correlation is computed by ranking the data and using the ranks in the Pearson product-moment correlation formula. In case of ties, the averaged ranks are used. Kendall tau-b correlation is a nonparametric measure of association based on the number of concordances and discordances in paired observations. Concordance occurs when paired observations vary together, and discordance occurs when paired observations vary differently. Hoeffding dependence correlation is a nonparametric measure of association that detects more general departures from independence. The statistic approximates a weighted sum over observations of chisquare statistics for $2 \times 2$ classification tables.

Where applicable, a risk ratio and a 95 percent confidence interval (CI) were used to compare results [28]. 
Probabilities of the ratios being the same were calculated using the Fisher exact test [29]. Values are presented as mean \pm SE.

\section{RESULTS}

\section{Baseline State}

Table 1 shows demographic features of the 63 veterans in this study. The veterans were evaluated between about 1 and $4.5 \mathrm{yr}$ after their last episode of mTBI. Thus, the veterans were likely evaluated and treated after the period of spontaneous recovery from their mTBIs. At baseline, almost half the subjects were taking an opioid medication alone or in a combination preparation with acetaminophen (Table 1). Almost three-quarters were taking NSAIDs either alone $(n=35,55.6 \%)$ or with an opioid ( $n=11,17.5 \%)$. Almost all subjects were taking an NSAID, an opioid, or both $(n=61,96.8 \%)$ to treat their headaches. None of the subjects were using a triptan medication for acute treatment of a migraine, and none used medication to prevent migraine headaches (see "Methods" section) at baseline. The headache medications used at the beginning of the study were continued during the 9 wk study period.

All the veterans in this study had headaches, PTSD, and an ND. The baseline PCL-M scores ranged from 52 to 82 with a mean of $70.40 \pm 0.92$ (Figure 2). Impaired olfaction was the most frequently recognized ND. The NDs were impaired olfaction ( $n=63)$, impaired balance ( $n=14)$, abnormal eye movements $(n=13)$, motor asymmetry $(n=2)$, and sensory change $(n=2)$. Twenty-nine veterans had $>1$ ND. The baseline distribution of headache types among the 63 veterans was 38 percent had tension-like headaches, 21 percent had migraine-like headaches, and 40 percent had mixed headaches. The baseline headache frequency was $13.30 \pm 0.71$ headaches per month, with 34 veterans (54\%) having chronic daily headaches; the baseline value for peak headache pain was $7.32 \pm 0.17$ out of 10 . At the onset of the study, the veterans had excessive daytime sleepiness with ESS scores of $16.00 \pm 0.31$, where ESS scores $>8$ indicate excessive daytime sleepiness. All veterans had ESS scores $>8$ at baseline.

We considered the associations among the outcomes at baseline by using several measures (Table 2). Figure 3 shows the associations among the outcome variables. At baseline, there were correlations between the PCL-M scores and headache frequency, ESS scores, and MOCA performance. The associations among PCL-M, headache frequency, and MOCA scores were logical. Higher PCL-M scores were associated with more frequent headaches and poorer performance on the MOCA, and higher MOCA scores were associated with lower headache frequency. Some associations were not expected. ESS scores were associated with PCL-M and MOCA scores, with subjects indicating less daytime sleepiness having greater PTSD severity and lower MOCA scores. The ESS findings may indicate that subjects with higher PTSD severity had less daytime sleepiness because of hypervigilance or because subjects underreported daytime sleepiness. The association between lower PTSD severity and more daytime sleepiness may explain why individuals who had higher MOCA scores also reported more daytime sleepiness. The association between olfaction scores and MOCA scores indicates that greater impairment of olfaction was weakly associated with higher MOCA scores.

\section{Completion of 9-Week Prazosin Introduction and Sleep Hygiene Counseling}

Veterans accepted the combination of prazosin and sleep hygiene counseling. Of the 63 veterans, 61 completed the dosing schedule for prazosin and all completed sleep hygiene counseling training. The two veterans who did not complete the prazosin dosing schedule initially did not accept this medication because they wanted to remain awake at night. No veteran had any of the potential adverse consequences of prazosin that we monitored: (1) postural light-headedness, (2) worsening of daytime somnolence, (3) skin rash, (4) bowel changes, (5) reduction in white blood cell count, or (6) liver function abnormalities.

Figure 2 shows the prominent improvements in headaches, daytime sleepiness, and MOCA test scores when reassessed $9 \mathrm{wk}$ after the initiation of prazosin medication combined with sleep hygiene counseling. Only 7 veterans had daily headaches and 15 had ESS scores $>8$. The increases in MOCA scores and reductions in headache frequency, pain intensity, and ESS scores were associated with a reduction in the mean PCL-M score from the baseline value of $70.40 \pm 0.92$ to $62.80 \pm$ 0.98 . In contrast, there was no change in the number of veterans with NDs or in the number or distribution of NDs. The olfaction scores also did not change from $4.77 \pm 0.27$ at baseline to $4.87 \pm 0.27$ at 9 wk.

Table 2 shows that greater PTSD severity was associated with lower MOCA scores, increased daytime 
Table 2.

Correlation analysis of baseline, 9 wk, and final outcomes. Values shown are from Pearson product-moment correlations (P). For each data cell, upper values are correlation values and lower values are $p$-values. Other correlation analyses performed were Spearman rank-order (S), Kendall tau-b $(\mathrm{K})$, and Hoeffding dependence $(\mathrm{H})$. Significant correlations $(p<0.05)$ are indicated by letters $\mathrm{P}, \mathrm{S}, \mathrm{K}, \mathrm{H}$.

\begin{tabular}{|c|c|c|c|c|c|}
\hline Outcome & Olfaction & HA Pain Severity & HA Frequency & ESS & MOCA \\
\hline \multicolumn{6}{|l|}{$\overline{\text { Baseline }}$} \\
\hline PCL-M & $\begin{array}{l}-0.05166 \\
0.69\end{array}$ & $\begin{array}{l}0.06436 \\
0.62\end{array}$ & $\begin{array}{l}\quad 0.40662 \\
<0.001 \\
\text { P, S, K, H }\end{array}$ & $\begin{array}{l}-0.29080 \\
0.02 \\
P, S, K, H\end{array}$ & $\begin{array}{l}-0.74623 \\
<0.001 \\
\text { P, S, K, H }\end{array}$ \\
\hline Olfaction & - & $\begin{array}{l}0.19384 \\
0.13\end{array}$ & $\begin{array}{c}-0.06263 \\
0.63\end{array}$ & $\begin{array}{l}-0.04234 \\
0.74\end{array}$ & $\begin{array}{c}-0.25428 \\
0.04 \\
P, K\end{array}$ \\
\hline HA Pain Severity & - & - & $\begin{array}{l}0.10132 \\
0.43\end{array}$ & $\begin{array}{l}-0.13020 \\
0.31\end{array}$ & $\begin{array}{l}0.10664 \\
0.40\end{array}$ \\
\hline HA Frequency & - & - & - & $\begin{array}{l}-0.11269 \\
0.38\end{array}$ & $\begin{array}{c}-0.34305 \\
0.006 \\
\text { P, S, K }\end{array}$ \\
\hline PCL-M & $\begin{array}{l}-0.15217 \\
0.23\end{array}$ & $\begin{array}{l}0.11478 \\
0.37\end{array}$ & $\begin{array}{c}0.32086 \\
0.01 \\
\text { P, S, K, H }\end{array}$ & $\begin{array}{l}-0.06232 \\
0.63\end{array}$ & $\begin{array}{c}-0.23939 \\
0.06 \\
\text { S, K }\end{array}$ \\
\hline Olfaction & - & $\begin{array}{l}0.01565 \\
0.90\end{array}$ & $\begin{array}{c}-0.24361 \\
0.05 \\
\text { S, K }\end{array}$ & $\begin{array}{l}0.14962 \\
0.24\end{array}$ & $\begin{array}{c}-0.10631 \\
0.41\end{array}$ \\
\hline HA Pain Severity & - & - & $\begin{array}{c}0.32159 \\
0.01 \\
\mathrm{P}, \mathrm{S}, \mathrm{K}, \mathrm{H}\end{array}$ & $\begin{array}{l}\quad 0.53514 \\
<0.001 \\
\text { P, S, K, H }\end{array}$ & $\begin{array}{l}-0.66598 \\
<0.001 \\
\text { P, S, K, H }\end{array}$ \\
\hline HA Frequency & - & - & - & $\begin{array}{l}0.27055 \\
0.03 \\
P\end{array}$ & $\begin{array}{l}-0.50143 \\
<0.001 \\
\text { P, S, K, H }\end{array}$ \\
\hline Olfaction & - & $\begin{array}{l}-0.00594 \\
0.96\end{array}$ & $\begin{array}{c}-0.08221 \\
0.52\end{array}$ & $\begin{array}{l}-0.00813 \\
0.95\end{array}$ & $\begin{array}{l}-0.00350 \\
0.98\end{array}$ \\
\hline HA Pain Severity & - & - & $\begin{array}{l}\quad 0.66147 \\
<0.001 \\
\text { P, S, K, H }\end{array}$ & $\begin{aligned} & 0.65788 \\
&< 0.001 \\
& \text { P, S, K, H }\end{aligned}$ & $\begin{array}{l}-0.60590 \\
<0.001 \\
\text { P, S, K, H }\end{array}$ \\
\hline HA Frequency & - & - & - & $\begin{array}{c}0.66735 \\
<0.001 \\
\text { P, S }\end{array}$ & $\begin{array}{l}-0.66394 \\
<0.001 \\
\text { P, S, K, H }\end{array}$ \\
\hline ESS & - & - & - & - & $\begin{array}{l}-0.76919 \\
<0.001 \\
\text { P, S, K, H }\end{array}$ \\
\hline
\end{tabular}




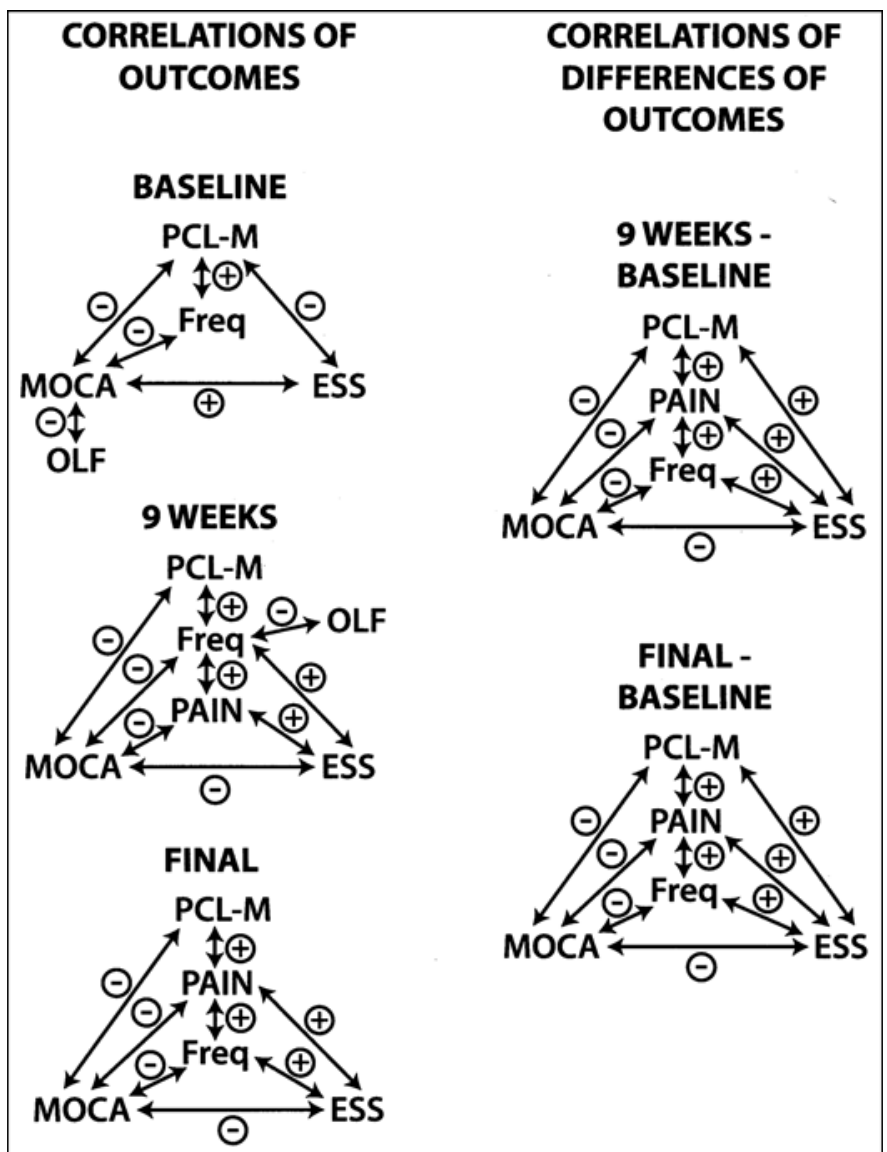

Figure 3.

Associations among outcome variables: Posttraumatic Stress Disorder Checklist-Military Version (PCL-M) scores, Montreal Cognitive Assessment (MOCA) scores, Epworth Sleepiness Scale (ESS) scores, headache pain intensity (PAIN), and headache frequency (Freq). Arrows indicate positive $(+)$ or negative $(-)$ associations. OLF = olfaction.

sleepiness, and more frequent headaches. The patterns of the associations among outcomes at 9 wk were logical (Figure 3). For example, higher MOCA scores were associated with less daytime sleepiness and lower headache frequency and pain. At this point, greater olfactory impairment was associated with more frequent headaches.

Table 3 shows the efficacy of the combination of prazosin treatment and sleep hygiene training for reduction in headache pain, headache frequency, and daytime sleepiness, measured by the ESS score. As noted, at the end of the 9 wk treatment induction period, two veterans were not taking prazosin. Therefore, Table 3 has data for the entire study group and for the 61 veterans who had completed the prazosin induction schedule and sleep hygiene training. More than half the subjects had a $>50$ percent reduction in pain and more than three-quarters had a $>50$ percent decrease in headache frequency and ESS scores.

\section{Months after Completion of Initiation Period for Sleep Treatment}

During the 6 mo follow-up period, the two veterans who did not take prazosin during the initial evaluation period decided to take prazosin. The prazosin dosing was increased weekly in the same manner as for the veterans in the initial 9 wk evaluation period. At the end of the 6 mo follow-up period, all the veterans were taking prazosin. Again, no veteran reported adverse effects from prazosin. During the 6 mo follow-up period, the veterans maintained the improvements they developed during the initial $9 \mathrm{wk}$ of treatment with prazosin and sleep hygiene counseling and often showed additional improvements. Figure 2 shows the continued improvements in headache pain, headache frequency, and daytime sleepiness. No veteran had daily headaches and only seven had ESS scores $>8$. The fraction of the subjects who had a $>50$ percent reduction in headache pain, headache frequency, and ESS scores compared with baseline was larger at the end of the study than at 9 wk (Table 3). The MOCA test scores at the end of the 6 mo follow-up period were significantly higher than the baseline scores (Table 4). The mean PCL-M scores at the end of the 6 mo follow-up period, $57.17 \pm$ 1.08 (Figure 2), were lower than after the 9 wk sleep treatment initiation period (Table 4). Figure 4 shows the

Table 3.

Effectiveness of combination of prazosin and sleep hygiene training for reduction of headache (HA) pain, HA frequency, and Epworth Sleepiness Scale (ESS) score. Values shown as $n(\%)$.

\begin{tabular}{lccc}
\hline \multicolumn{1}{c}{ Outcome } & $\begin{array}{c}\mathbf{9} \text { wk } \\
(\boldsymbol{n}=\mathbf{6 3 )}\end{array}$ & $\begin{array}{c}\text { 9 wk, Taking Prazosin } \\
(\boldsymbol{n}=\mathbf{6 1})\end{array}$ & $\begin{array}{c}\text { 6 mo Later } \\
(\boldsymbol{n}=\mathbf{6 3})\end{array}$ \\
\hline 50\% Pain Reduction & $36(57.1)$ & $36(59.0)$ & $52(82.5)$ \\
$50 \%$ HA Frequency Reduction & $53(84.1)$ & $53(86.9)$ & $55(87.2)$ \\
$50 \%$ Reduction in ESS Score & $48(76.2)$ & $48(78.7)$ & $56(88.9)$ \\
\hline \hline
\end{tabular}


empirical distribution of the PCL-M scores at the three evaluation points. The empirical distribution curves show an overall progressive shift from higher to lower levels of PTSD severity during this study. At the end of the $9 \mathrm{wk}$ period, 4 veterans had PCL-M scores $<50$, and at the end of the 6 mo follow-up period, 11 veterans had PCL-M scores of $<50$.

In contrast to the progressive reduction in the PCL-M scores, the olfaction scores did not improve (Figure 2). One veteran, who initially had two NDs, had only impaired olfaction after 6 mo. No other veteran had a change in the number or type of NDs. All the veterans continued to have NDs after the 6 mo follow-up period. The olfaction scores at the end of the 6 mo follow-up period, $4.88 \pm 0.28$, were not different from the scores at baseline or at 9 wk (Table 4).

At the end of the study, increased daytime sleepiness was associated with lower MOCA scores and worst headaches (Table 2, Figure 3). Higher pain scores and headache frequency were associated with lower MOCA scores. Greater headache pain was associated with more frequent headaches. Higher PCL-M scores were associated with lower MOCA scores and more frequent headaches.

Table 4 shows the differences in outcome values at $9 \mathrm{wk}$ and the end of the study compared with baseline values and a comparison of the $9 \mathrm{wk}$ and final outcomes. The olfaction scores did not change during the study. In contrast, there were progressive reductions in headache severity, daytime sleepiness, PTSD severity, and MOCA scores. The final MOCA scores were not higher than the values at $9 \mathrm{wk}$, possibly reflecting a ceiling effect on the MOCA scores.

Table 5 shows the correlations between the differences in the outcome values at 9 wk versus baseline.
Reductions in PCL-M scores were associated with reductions in daytime sleepiness, reductions in headache pain, and improvements in MOCA scores. Reductions in daytime sleepiness were associated with reductions in headache pain and frequency and higher MOCA scores. Headache pain was associated with headache frequency, indicating that these symptoms improved in parallel. Improvements in MOCA scores were associated with reductions in PCL-M scores, daytime sleepiness, and headache pain and frequency.

Table 5 also shows the correlations between differences in the final outcomes versus the baseline values. The patterns of the associations among the outcome variables were identical for the measurements at 9 wk-baseline or the final-baseline values (Figure 3).

\section{DISCUSSION}

This was an observational study without a control group. We previously discussed the potential biases inherent in the analysis of the larger 74-veteran study group [10] that included the 63 veterans reported in this study. The reservations that we stated for the 74-veteran study group [10] apply to this study group. The intervention used was designed to attenuate nightmares, a manifestation of PTSD. We are not aware of any interventions that would have reversed the most common ND we observed, reduced olfaction.

Impaired sleep commonly accompanies PTSD in U.S. OIF/OEF veterans [30-31]. This study employed an intervention to improve sleep by reducing the frequency and severity of nightmares that disrupt sleep [22]. In our

Table 4.

Variable mean \pm standard error of the mean values at baseline. Also, differences $(\Delta)$ between baseline values, values at 9 wk after start of prazosin and sleep hygiene counseling treatment, and final measurements made and differences between 9 wk and final values. $p$-Values were adjusted for multiple tests (null hypothesis = difference between two time points was zero).

\begin{tabular}{lcccc}
\hline \multicolumn{1}{c}{ Variable } & \multicolumn{1}{c}{ Baseline } & $\Delta$ (Baseline-9 wk) & $\Delta$ (Baseline-Final) & $\Delta$ (9 wk-Final) \\
\hline Olfaction Score & $4.13 \pm 0.11$ & $-0.0925 \pm 0.18$ & $-0.0635 \pm 0.15$ & $0.0318 \pm 0.14$ \\
PCL-M Score & $70.00 \pm 0.96$ & $6.75 \pm 0.41^{*}$ & $11.80 \pm 0.66^{*}$ & $5.06 \pm 0.31^{*}$ \\
HA Pain Intensity & $7.35 \pm 0.17$ & $3.35 \pm 0.22^{*}$ & $4.57 \pm 0.22^{*}$ & $1.22 \pm 0.08^{*}$ \\
HA Frequency (No./4 wk) & $13.30 \pm 0.71$ & $8.57 \pm 0.69^{*}$ & $10.90 \pm 0.84^{*}$ & $2.32 \pm 0.69^{\dagger}$ \\
ESS Score & $16.00 \pm 0.31$ & $8.92 \pm 0.42^{*}$ & $11.30 \pm 0.44^{*}$ & $2.38 \pm 0.15^{*}$ \\
MOCA Score & $24.30 \pm 0.26$ & $-4.06 \pm 0.33^{*}$ & $-4.29 \pm 0.33^{*}$ & $-0.22 \pm 0.11$ \\
\hline
\end{tabular}

${ }^{*} p<0.001$.

${ }^{\dagger} p<0.005$.

ESS = Epworth Sleepiness Scale, HA = headache, MOCA = Montreal Cognitive Assessment, PCL-M = Posttraumatic Stress Disorder Checklist-Military Version. 


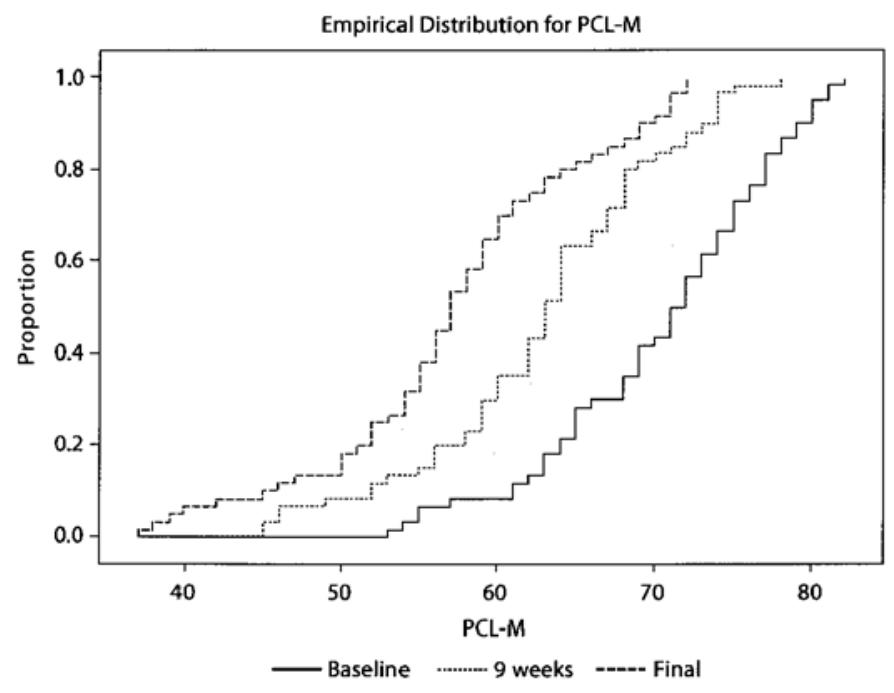

Figure 4.

Empirical distribution of Posttraumatic Stress Disorder Checklist-Military Version (PCL-M) scores for veterans at baseline, after completion of $9 \mathrm{wk}$ sleep hygiene training and prazosin introduction period, and at study completion.

prior study [10], we observed that in response to sleep hygiene counseling and prazosin at bedtime, headache pain and frequency declined, ESS scores decreased, and MOCA scores increased. In this study, we examined whether the intervention to improve sleep altered PTSD severity, the prevalence of NDs, or the severity of olfactory impairment. We found progressive reductions in PCL-M scores, suggesting that reduction in PTSD severity occurred in parallel with the improvements in clinical manifestations (Figure 2). We found consistent associations among ESS, MOCA, and PCL-M scores and headache severity (Figure 3). The nature of this study does not allow us to discern causality. We cannot distinguish between the possibilities of improved sleep independently reducing PTSD severity, headache severity, and MOCA scores versus improved sleep leading to reduced PTSD severity and the reduced PTSD severity driving improvements in headaches and cognitive functioning. As we previously discussed [10], sleep deprivation will adversely affect cognitive functioning and pain thresholds and trigger headaches. Sleep deprivation impairs attention, working memory, long-term memory, and decision-making [32]; consequently, it is not surprising that improving sleep would be associated with improved performance on the MOCA. Sleep deprivation will cause or aggravate headaches [18].
In studies by others, prazosin treatment resulted in reduction in aspects of PTSD severity, as demonstrated by a lower score for the recurrent distressing dreams item of the Clinician-Administered PTSD Scale [22,33]. The effects of prazosin were presumed to be mediated primarily by reducing nightmares; however, prazosin may also directly reduce some aspects of PTSD symptoms, such as hyperarousal, by attenuating alpha-adrenergic activity in the central nervous system [21-22,34]. We found that PTSD severity, measured with the PCL-M scale, was sequentially reduced at $9 \mathrm{wk}$ and on the final measure (Figure 4). The patterns of the associations among the outcome variables for measurements made at $9 \mathrm{wk}$, the final measurements, and the difference of measurements made at 9 wk or at 6 mo compared with the baseline values were remarkably similar (Figure 3). The only variant associations were for the baseline ESS values, which were positively correlated with MOCA and negatively correlated with PCL-M scores. As we previously suggested, possible explanations are that at baseline, veterans with more severe PTSD reported less daytime sleepiness because of hypervigilance or because veterans with more severe PTSD were underreporting daytime sleepiness.

The intervention we used to improve sleep did not ameliorate NDs. This suggests that the NDs we identified were not the result of impaired sleep. The most frequent ND we identified was impaired olfaction, and we could not identify interactions between impaired sleep and impaired olfaction. In addition, the subjects had improvements in cognitive performance and headaches without change in the frequency of NDs or the severity of impaired olfaction. This suggests that the NDs we identified were not driving the severity of headaches or MOCA performance. In a study of mTBI in a civilian cohort, impaired olfaction was identified in about 30 percent of subjects, but impaired olfaction did not correlate with the presence of posttraumatic symptoms [35]. We believe that the NDs we identified were markers of persisting cerebral injury. Imaging studies of U.S. OIF/OEF military personnel and veterans have disclosed subtle neurological injury that included orbital frontal cortex and white matter [36-37]. Injury to orbital frontal cortex occurs in subjects who had impaired olfaction associated with head trauma [38-40].

The lack of correlation between NDs and symptoms following mTBI raises the question as to whether NDs have any relationship to symptoms in veterans who experienced combat mTBI. We wish to advance the following 
RUFF et al. mTBI improvements correlate with PTSD severity and improved sleep

Table 5.

Correlation analysis of difference $(\Delta)$ of outcomes between 9 wk and baseline and between final and baseline. Correlations are defined as shown in Table 2.

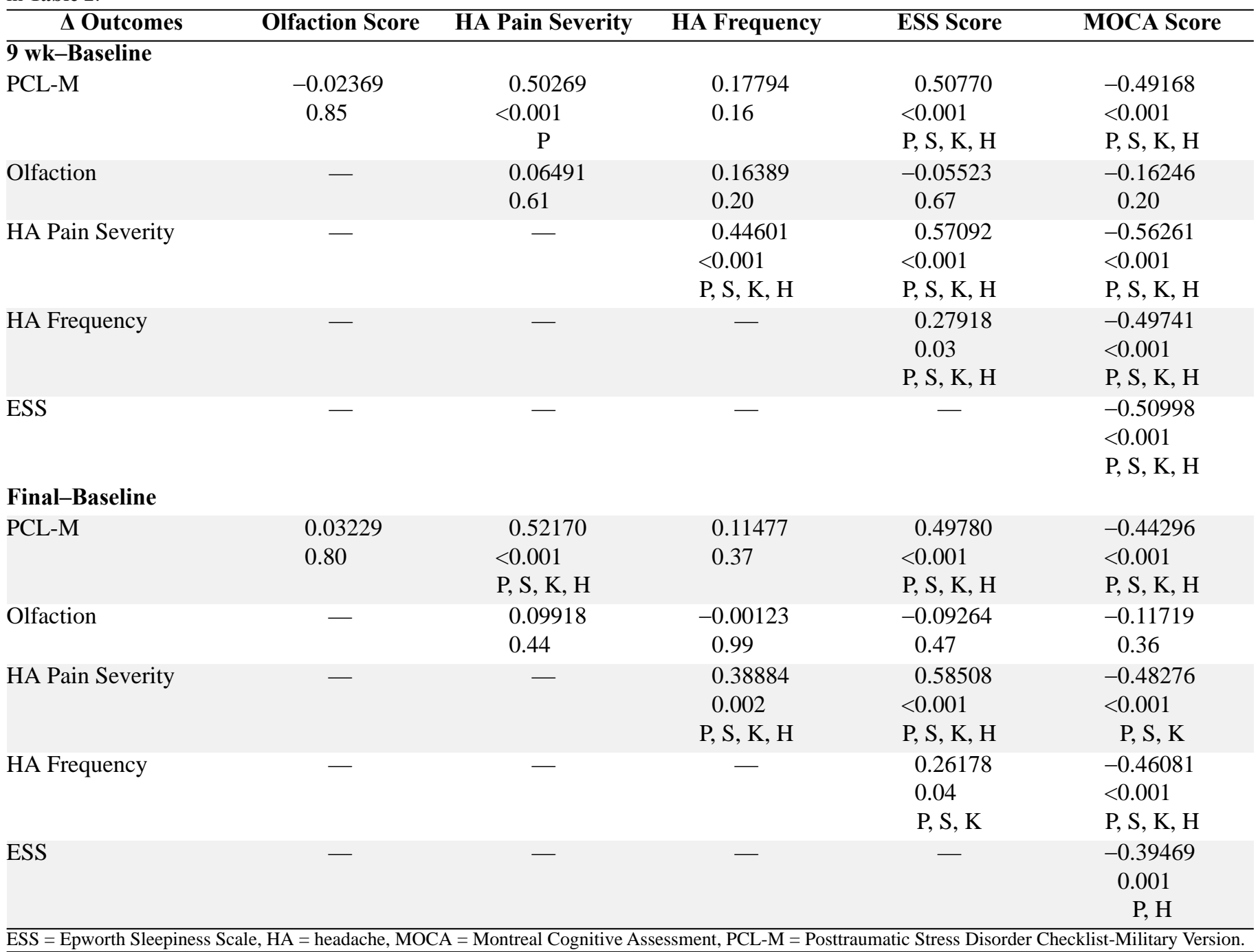

hypotheses. First, the mild NDs associated with mTBI are not directly contributing to severity of symptoms that emerge following mTBI. Of note among soldiers who returned from OIF deployment, after adjustment for PTSD and depression, the only posttraumatic symptom that was associated with mTBI was headache [41]. Second, for combat mTBI, impaired sleep and PTSD severity modulate most symptoms following mTBI. Several articles have suggested that PTSD strongly influences the symptoms associated with mTBI in deployed military personnel [31,41-43]. This study and other studies suggest that altered sleep due to PTSD contributes to symptoms that emerge following combat mTBI [31,44]. Figure 3 shows that headache pain and frequency and
MOCA scores were associated with ESS scores, with PCL-M scores, or with both. Third, the role of mild cerebral injury associated with mTBI in the symptoms that emerge following combat mTBI may be primarily to increase the likelihood that a psychologically traumatic event results in PTSD.

Several tracts of evidence suggest that mTBI may increase the likelihood that PTSD emerges following a traumatic event. In a study of civilian trauma in Australia, the prevalence of PTSD following mTBI was 6 percent, which was higher (odds ratio $=1.9,95 \% \mathrm{CI}=1.1-$ 3.4) than for trauma without head injury [45]. The prevalence of PTSD following combat mTBI is understandably greater than after civilian mTBI. In OIF/OEF, 
combat mTBI was likely to be associated with events that threatened the life of a soldier, led to injury or death of comrades, and were associated with injury or death of Iraqi or Afghani civilians or combatants. About 40 percent of OIF/OEF military personnel and veterans with combat-acquired mTBI had coexistent PTSD [5,46-47]. In OIF, military personnel who had an episode of mTBI with LOC had a PTSD prevalence of 43.9 percent compared with 16.2 percent prevalence among soldiers without TBI and 9.1 percent with no injury [41]. Other studies reported that mTBI predisposed veterans to PTSD [48]. If one considers the OIF/OEF veteran cohort in Figure 1, among the group of 126 veterans with at least one episode of mTBI associated with LOC, 85 veterans had PTSD, 65 had an ND, 63 had PTSD and an ND, and 39 had neither [13]. The relative risk of developing PTSD for a veteran with an ND from this group of veterans with mTBI was 2.69 (95\% CI $=1.92-3.76, p<0.001)$ compared with veterans without an ND. Hence, among the group of veterans with mTBI associated with LOC, having an ND increased the likelihood of PTSD by $>2.5-$ fold. However, these observations do not clarify the mechanisms by which mTBI is associated with PTSD.

"Data suggest that PTSD is associated with over activation of the amygdala due to a lack of inhibitory control by ventromedial prefrontal cortex, as well as deficient hippocampal function” [49, p. 232]. Monozygotic twin studies of Vietnam veterans suggest that subtle ("soft") NDs, which likely resulted from mild inherited alterations in cerebral function, may predispose to PTSD [50]. The 45 neurological signs measured in the Vietnam veterans were similar to the elements of the neurological examination performed in this study. However, olfaction was not tested in the twin studies. Monozygotic twins were studied where one twin was in combat and the other not. Among twins pairs where the twin who had been in combat developed PTSD, both twins had a higher prevalence of neurological soft signs [50] or gray matter abnormalities in the right hippocampus, pregenual anterior cingulate cortex, and left and right insular cortex [51] than the twin pairs where the combat-exposed twin did not have PTSD. The presence of similar patterns of NDs among both of the monozygotic twins suggests that the observed NDs were genetic in origin.

While the twin studies suggest that mild dysfunction of the frontal or temporal cortex may potentiate development of PTSD, other studies suggest that severe focal cerebral injury may protect against development of
PTSD. The Vietnam Head Injury Program (VHIP) evaluated veterans with moderate or severe combat TBI who had penetrating cerebral injuries [49]. TBI was classified based on lesion location, and the prevalence of PTSD was compared across groups with different injury loci. Veterans with ventromedial frontal or amygdala injuries had lower PTSD prevalence. The difference in findings between the monozygotic twin studies and the VHIP is likely due to differences in the severity of cerebral dysfunction. Veterans in the twin studies had subtle deficits in performance and mild cerebral imaging deficits compared with the veterans with penetrating injuries in the VHIP study. Mild injury may potentiate the development of PTSD by altering normal interactions among the amygdala, ventromedial frontal cortex, and hippocampus. In contrast, severe injuries to areas critical to PTSD may prevent "the 'super-normal' levels of fear/anxiety that define PTSD” [49, p. 235-36]. For OIF/OEF veterans, the risk of an individual with combat TBI developing PTSD is higher for mTBI than severe TBI [46]. Also, the penetrating injuries studied in the VHIP study were more focal and less likely to be associated with the diffuse axonal injury seen in concussive closed head injury. Perhaps not only the loci but also the severity and mechanism of injury in mTBI influence the likelihood that PTSD develops following a psychologically traumatic event. The areas of the brain with altered function identified by functional imaging in PTSD, including ventromedial frontal lobes and anterior medial temporal lobes [5253], are included within the areas that are damaged in mTBI [36-37,54-55]. The episodes of mTBI with LOC may have slightly injured the inferior frontal lobes, as suggested by the associated finding of impaired olfaction, without severe enough injury to reduce the likelihood of PTSD developing. Thus, the cerebral injuries produced by mTBI with LOC may have resulted in frontal lobe injury without destroying cerebral regions needed to generate PTSD.

Many recognized factors influence the likelihood that a person develops PTSD following a psychologically traumatic event. As previously discussed, the presence of some soft neurological signs may predispose to PTSD and destruction of the amygdala or ventromedial frontal cortex may protect against PTSD. Aggressively treating combat pain with morphine is associated with reduced PTSD development [56]. Psychological resiliency and strong support systems reduce the likelihood of PTSD [57]. The see-saw illustration (Figure 5) shows that some 
factors reduce and other factors increase the likelihood that an individual will develop PTSD following an episode of combat trauma. This figure is not intended to show all the factors that can influence the genesis of PTSD, nor is it meant to suggest that factors shown are equally important for a given individual. We suggest, as shown in Figure 5, that mTBI may increase the risk for developing PTSD.

\section{CONCLUSIONS}

We found that prazosin combined with sleep hygiene counseling reduced the severity of headaches, PTSD, and daytime sleepiness. There were no changes in the presence of NDs. Hence, the improvements in headache frequency and pain severity were associated with reductions in daytime sleepiness, which likely reflected improved sleep, and reduction in PTSD severity. The benefits of improved sleep continued during the 6 mo follow-up period. When measurements were made after the start of the prazosin and sleep hygiene intervention, headache symptoms improved in parallel with reductions in PCL-M scores and daytime sleepiness. We cannot discern from this study whether (1) improving sleep led to reduced perceived severity of PTSD and separately to reduced headache symptoms and improved MOCA scores or (2) improved sleep reduced PTSD severity and reduced PTSD severity led to reduced headache severity and improved performance on the MOCA. We suggest that the NDs we observed were only markers of mild brain damage due to mTBI. While NDs did not drive the improvements in headache symptoms and MOCA scores, we suggest that mTBI with LOC may predispose to development of PTSD

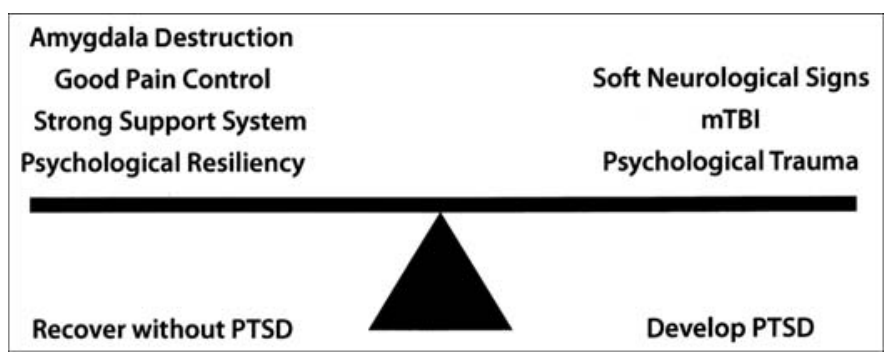

Figure 5.

See-saw cartoon showing factors that may influence genesis of posttraumatic stress disorder (PTSD) following episode of combat trauma. $\mathrm{mTBI}=$ mild traumatic brain injury. in response to a psychologically traumatic event. The findings in this study need to be considered with caution until they are supported in a controlled clinical trial.

\section{ACKNOWLEDGMENTS}

\section{Author Contributions:}

Additional details are provided in the initial report of the prazosin/ sleep hygiene study [10].

Assisted with study design: S. S. Ruff.

Contributed to criteria for subject selection: R. G. Riechers, T. Piero. Wrote and edited manuscript: R. L. Ruff, R. G. Riechers, X.-F. Wang, T. Piero, S. S. Ruff.

Statistical analysis: X.-F. Wang.

Assisted with data interpretation: R. G. Riechers.

Provided sleep hygiene counseling and headache education: S. S. Ruff.

Performed neurological examinations: R. L. Ruff.

Collected data on daytime sleepiness and headache patterns: R. L. Ruff. Performed cognitive screening using MOCA: R. L. Ruff.

Prescribed prazosin and monitored prazosin usage: R. L. Ruff.

Examined subjects: T. Piero, S. S. Ruff.

Closely followed clinical state of veterans during study: T. Piero.

Financial Disclosures: The authors have declared that no competing interests exist.

Funding/Support: This material is based on work supported by Department of Veterans Affairs, Office of Research and Development, Rehabilitation Research and Development Service, 2010 Magnuson Award (R. L. Ruff) and Functional Electrical Stimulation Center of Excellence Award (R. L Ruff, Co-Principal Investigator).

Institutional Review: The CVAMC Institutional Review Board reviewed the data in this report, approved waiver of HIPAA (Health Insurance Portability and Accountability Act of 1996) authorization, granted a waiver of informed consent, and approved submission of the data in this manuscript for publication. Veterans did not sign consent forms. We collected information from the veterans in a uniform and prospective manner.

Participant Follow-Up: The authors plan to inform participants of the publication of this study.

\section{REFERENCES}

1. Taber KH, Warden DL, Hurley RA. Blast-related traumatic brain injury: what is known? J Neuropsychiatry Clin Neurosci. 2006;18(2):141-45. [PMID:16720789] http://dx.doi.org/10.1176/appi.neuropsych.18.2.141

2. Warden DL. Military TBI during the Iraq and Afghanistan wars. J Head Trauma Rehabil. 2006;21(5):398-402. [PMID:16983225] http://dx.doi.org/10.1097/00001199-200609000-00004

3. Theeler BJ, Flynn FG, Erickson JC. Headaches after concussion in US soldiers returning from Iraq or Afghanistan. 
Headache. 2010;50(8):1262-72. [PMID:20553333]

http://dx.doi.org/10.1111/j.1526-4610.2010.01700.x

4. Clark ME, Bair MJ, Buckenmaier CC 3rd, Gironda RJ, Walker RL. Pain and combat injuries in soldiers returning from Operations Enduring Freedom and Iraqi Freedom: implications for research and practice. J Rehabil Res Dev. 2007;44(2):179-94. [PMID:17551872]

http://dx.doi.org/10.1682/JRRD.2006.05.0057

5. Gironda RJ, Clark ME, Ruff RL, Chait S, Craine M, Walker $\mathrm{R}$, Scholten J. Traumatic brain injury, polytrauma, and pain: challenges and treatment strategies for the polytrauma rehabilitation. Rehabil Psychol. 2009;54(3):247-58.

[PMID:19702423] http://dx.doi.org/10.1037/a0016906

6. Lew HL, Lin P-H, Fuh J-L, Wang S-J, Clark DJ, Walker WC. Characteristics and treatment of headache after traumatic brain injury: a focused review. Am J Phys Med Rehabil. 2006;85(7):619-27. [PMID:16788394]

http://dx.doi.org/10.1097/01.phm.0000223235.09931.c0

7. Roberts RJ. Impact on the brain. Sci Am Mind. 2008; 19:51-57.

http://dx.doi.org/10.1038/scientificamericanmind1208-50

8. Raskind MA, Peskind ER, Hoff DJ, Hart KL, Holmes HA, Warren D, Shofer J, O’Connell J, Taylor F, Gross C, Rohde $\mathrm{K}$, McFall ME. A parallel group placebo controlled study of prazosin for trauma nightmares and sleep disturbance in combat veterans with post-traumatic stress disorder. Biol Psychiatry. 2007;61(8):928-34. [PMID:17069768] http://dx.doi.org/10.1016/j.biopsych.2006.06.032

9. Calohan J, Peterson K, Peskind ER, Raskind MA. Prazosin treatment of trauma nightmares and sleep disturbance in soldiers deployed in Iraq. J Trauma Stress. 2010;23(5): 645-48. [PMID:20931662] http://dx.doi.org/10.1002/jts.20570

10. Ruff RL, Ruff SS, Wang X-F. Improving sleep: initial headache treatment in OIF/OEF veterans with blastinduced mild traumatic brain injury. J Rehabil Res Dev. 2009;46(9):1071-84. [PMID:20437313] http://dx.doi.org/10.1682/JRRD.2009.05.0062

11. Malec JF, Brown AW, Leibson CL, Flaada JT, Mandrekar JN, Diehl NN, Perkins PK. The Mayo classification system for traumatic brain injury severity. J Neurotrauma. 2007;24(9):1417-24. [PMID:17892404]

http://dx.doi.org/10.1089/neu.2006.0245

12. Donnelly KT, Donnelly JP, Dunnam M, Warner GC, Kittleson CJ, Constance JE, Bradshaw CB, Alt M. Reliability, sensitivity, and specificity of the VA traumatic brain injury screening tool. J Head Trauma Rehabil. 2011;26(6):439-53. [PMID:21386716] http://dx.doi.org/10.1097/HTR.0b013e3182005de3

13. Ruff RL, Ruff SS, Wang X-F. Headaches among Operation Iraqi Freedom/Operation Enduring Freedom veterans with mild traumatic brain injury associated with exposures to explosions. J Rehabil Res Dev. 2008;45(7):941-52.

[PMID:19165684]

http://dx.doi.org/10.1682/JRRD.2008.02.0028

14. Doty RL, Marcus A, Lee WW. Development of the 12-item Cross-Cultural Smell Identification Test (CC-SIT). Laryngoscope. 1996;106(3 Pt 1):353-56. [PMID:8614203] http://dx.doi.org/10.1097/00005537-199603000-00021

15. Doty RL. Olfaction. Annu Rev Psychol. 2001;52:423-52. [PMID:11148312] http://dx.doi.org/10.1146/annurev.psych.52.1.423

16. Nasreddine ZS, Phillips NA, Bédirian V, Charbonneau S, Whitehead V, Collin I, Cummings JL, Chertkow H. The Montreal Cognitive Assessment, MoCA: a brief screening tool for mild cognitive impairment. J Am Geriatr Soc. 2005;53(4):695-99. [PMID:15817019] http://dx.doi.org/10.1111/j.1532-5415.2005.53221.x

17. Zadikoff C, Fox SH, Tang-Wai DF, Thomsen T, de Bie RM, Wadia P, Miyasaki J, Duff-Canning S, Lang AE, Marras C. A comparison of the Mini Mental State Exam to the Montreal cognitive assessment in identifying cognitive deficits in Parkinson's disease. Mov Disord. 2008;23(2):297-99.

[PMID:18044697]

http://dx.doi.org/10.1002/mds.21837

18. Headache Classification Subcommittee of the International Headache Society. The International Classification of Headache Disorders, 2nd edition. Cephalgia. 2004; 24(Suppl 1):9-160.

19. Department of Veterans Affairs. National Center for PTSD: Using the PTSD Checklist (PCL). [Internet]. Washington (DC): Department of Veterans Affairs; 2010. Available from: http://www.ptsd.va.gov/professional/pages/assessments/ ptsd-checklist.asp

20. Johns MW. Sensitivity and specificity of the Multiple Sleep Latency Test (MSLT), the Maintenance of Wakefulness Test and the Epworth Sleepiness Scale: failure of the MSLT as a gold standard. J Sleep Res. 2000;9(1):5-11.

[PMID:10733683]

http://dx.doi.org/10.1046/j.1365-2869.2000.00177.x

21. Boehnlein JK, Kinzie JD. Pharmacologic reduction of CNS noradrenergic activity in PTSD: the case for clonidine and prazosin. J Psychiatr Pract. 2007;13(2):72-78.

[PMID:17414682]

http://dx.doi.org/10.1097/01.pra.0000265763.79753.c1

22. Taylor FB, Martin P, Thompson C, Williams J, Mellman TA, Gross C, Peskind ER, Raskind MA. Prazosin effects on objective sleep measures and clinical symptoms in civilian trauma posttraumatic stress disorder: a placebo-controlled study. Biol Psychiatry. 2008;63(6):629-32.

[PMID:17868655]

http://dx.doi.org/10.1016/j.biopsych.2007.07.001 
23. Agresti A, editor. Chapter 2. Association analysis. In: An introduction to categorical data analysis. New York (NY): John Wiley \& Sons; 1996.

24. Verbeke G, Molenberghs G. Linear mixed models for longitudinal data. New York (NY): Springer; 2000.

25. Coggon D. Statistics in clinical practice. 2nd ed. New York (NY): Wiley-Blackwell; 2003.

26. Belle GV, Fisher LD, Heagerty PJ, Lumley TS, editors. Chapter 9. Correlation tests. In: Biostatistics: a methodology for the health sciences. New York (NY): John Wiley \& Sons; 2004.

27. Benjamini Y, Hochberg Y. Controlling the false discovery rate: a practical and powerful approach to multiple testing. J R Stat Soc Series B Stat Methodol. 1995;57:289-300.

28. Morris JA, Gardner MJ. Calculating confidence intervals for relative risks (odds ratios) and standardised ratios and rates. BMJ. 1988;296(6632):1313-16. [PMID:3133061] http://dx.doi.org/10.1136/bmj.296.6632.1313

29. Agresti A. A survey of exact inference for contegency tables. Stat Sci. 1992;7:131-53. http://dx.doi.org/10.1214/ss/1177011454

30. Pietrzak RH, Morgan CA 3rd, Southwick SM. Sleep quality in treatment-seeking veterans of Operations Enduring Freedom and Iraqi Freedom: the role of cognitive coping strategies and unit cohesion. J Psychosom Res. 2010;69(5): 441-48. [PMID:20955863]

http://dx.doi.org/10.1016/j.jpsychores.2010.07.002

31. Lew HL, Pogoda TK, Hsu PT, Cohen S, Amick MM, Baker E, Meterko M, Vanderploeg RD. Impact of the "polytrauma clinical triad” on sleep disturbance in a Department of Veterans Affairs outpatient rehabilitation setting. Am J Phys Med Rehabil. 2010;89(6):437-45. [PMID:20489391] http://dx.doi.org/10.1097/PHM.0b013e3181ddd301

32. Alhola P, Polo-Kantola P. Sleep deprivation: impact on cognitive performance. Neuropsychiatr Dis Treat. 2007; 3(5):553-67. [PMID:19300585]

33. Boynton L, Bentley J, Strachan E, Barbato A, Raskind M. Preliminary findings concerning the use of prazosin for the treatment of posttraumatic nightmares in a refugee population. J Psychiatr Pract. 2009;15(6):454-59.

[PMID:19934720]

http://dx.doi.org/10.1097/01.pra.0000364287.63210.92

34. Dierks MR, Jordan JK, Sheehan AH. Prazosin treatment of nightmares related to posttraumatic stress disorder. Ann Pharmacother. 2007;41(6):1013-17. [PMID:17504838] http://dx.doi.org/10.1345/aph.1H588

35. de Kruijk JR, Leffers P, Menheere PP, Meerhoff S, Rutten J, Twijnstra A. Olfactory function after mild traumatic brain injury. Brain Inj. 2003;17(1):73-78.

[PMID:12519649]

http://dx.doi.org/10.1080/0269905021000010221
36. Mac Donald CL, Johnson AM, Cooper D, Nelson EC, Werner NJ, Shimony JS, Snyder AZ, Raichle ME, Witherow JR, Fang R, Flaherty SF, Brody DL. Detection of blastrelated traumatic brain injury in U.S. military personnel. N Engl J Med. 2011;364(22):2091-2100. [PMID:21631321] http://dx.doi.org/10.1056/NEJMoa1008069

37. Peskind ER, Petrie EC, Cross DJ, Pagulayan K, McCraw K, Hoff D, Hart K, Yu C-E, Raskind MA, Cook DG, Minoshima S. Cerebrocerebellar hypometabolism associated with repetitive blast exposure mild traumatic brain injury in 12 Iraq war Veterans with persistent post-concussive symptoms. Neuroimage. 2011;54(Suppl 1):S76-82.

[PMID:20385245]

http://dx.doi.org/10.1016/j.neuroimage.2010.04.008

38. Doty RL, Yousem DM, Pham LT, Kreshak AA, Geckle R, Lee WW. Olfactory dysfunction in patients with head trauma. Arch Neurol. 1997;54(9):1131-40. [PMID:9311357] http://dx.doi.org/10.1001/archneur.1997.00550210061014

39. Yousem DM, Geckle RJ, Bilker WB, McKeown DA, Doty RL. Posttraumatic olfactory dysfunction: MR and clinical evaluation. AJNR Am J Neuroradiol. 1996;17(6):1171-79. [PMID:8791933]

40. Costanzo RM, Miwa T. Posttraumatic olfactory loss. Adv Otorhinolaryngol. 2006;63:99-107. [PMID:16733335] http://dx.doi.org/10.1159/000093753

41. Hoge CW, McGurk D, Thomas JL, Cox AL, Engel CC, Castro CA. Mild traumatic brain injury in U.S. Soldiers returning from Iraq. N Engl J Med. 2008;358(5):453-63. [PMID:18234750] http://dx.doi.org/10.1056/NEJMoa072972

42. Vanderploeg RD, Belanger HG, Curtiss G. Mild traumatic brain injury and posttraumatic stress disorder and their associations with health symptoms. Arch Phys Med Rehabil. 2009;90(7):1084-93. [PMID:19577020]

http://dx.doi.org/10.1016/j.apmr.2009.01.023

43. Belanger HG, Kretzmer T, Vanderploeg RD, French LM. Symptom complaints following combat-related traumatic brain injury: relationship to traumatic brain injury severity and posttraumatic stress disorder. J Int Neuropsychol Soc. 2010;16(1):194-99. [PMID:19758488] http://dx.doi.org/10.1017/S1355617709990841

44. Belanger HG, Spiegel E, Vanderploeg RD. Neuropsychological performance following a history of multiple selfreported concussions: a meta-analysis. J Int Neuropsychol Soc. 2010;16(2):262-67. [PMID:20003581] http://dx.doi.org/10.1017/S1355617709991287

45. Bryant RA, O’Donnell ML, Creamer M, McFarlane AC, Clark CR, Silove D. The psychiatric sequelae of traumatic injury. Am J Psychiatry. 2010;167(3):312-20.

[PMID:20048022]

http://dx.doi.org/10.1176/appi.ajp.2009.09050617 
46. Carlson K, Kehle S, Meis L, Greer N, MacDonald R, Rutks I, Wilt TJ. The assessment and treatment of individuals with history of traumatic brain injury and post-traumatic stress disorder: a systematic review of the evidence. Washington (DC): Department of Veterans Affairs, Health Services Research and Development Service; 2009. p. 72.

47. Lew HL, Otis JD, Tun C, Kerns RD, Clark ME, Cifu DX. Prevalence of chronic pain, posttraumatic stress disorder, and persistent postconcussive symptoms in OIF/OEF veterans: polytrauma clinical triad. J Rehabil Res Dev. 2009; 46(6):697-702. [PMID:20104399] http://dx.doi.org/10.1682/JRRD.2009.01.0006

48. Pietrzak RH, Johnson DC, Goldstein MB, Malley JC, Southwick SM. Posttraumatic stress disorder mediates the relationship between mild traumatic brain injury and health and psychosocial functioning in veterans of Operations Enduring Freedom and Iraqi Freedom. J Nerv Ment Dis. 2009;197(10):748-53. [PMID:19829203] http://dx.doi.org/10.1097/NMD.0b013e3181b97a75

49. Koenigs M, Huey ED, Raymont V, Cheon B, Solomon J, Wassermann EM, Grafman J. Focal brain damage protects against post-traumatic stress disorder in combat veterans. Nat Neurosci. 2008;11(2):232-37. [PMID:18157125] http://dx.doi.org/10.1038/nn2032

50. Gurvits TV, Metzger LJ, Lasko NB, Cannistraro PA, Tarhan AS, Gilbertson MW, Orr SP, Charbonneau AM, Wedig MM, Pitman RK. Subtle neurologic compromise as a vulnerability factor for combat-related posttraumatic stress disorder: results of a twin study. Arch Gen Psychiatry. 2006;63(5):571-76. [PMID:16651514]

http://dx.doi.org/10.1001/archpsyc.63.5.571

51. Kasai K, Yamasue H, Gilbertson MW, Shenton ME, Rauch SL, Pitman RK. Evidence for acquired pregenual anterior cingulate gray matter loss from a twin study of combatrelated posttraumatic stress disorder. Biol Psychiatry. 2008;63(6):550-56. [PMID:17825801] http://dx.doi.org/10.1016/j.biopsych.2007.06.022

52. Whalley MG, Rugg MD, Smith AP, Dolan RJ, Brewin CR. Incidental retrieval of emotional contexts in post-traumatic stress disorder and depression: an fMRI study. Brain Cogn. 2009;69(1):98-107. [PMID:18614265] http://dx.doi.org/10.1016/j.bandc.2008.05.008

53. Sailer U, Robinson S, Fischmeister FP, König D, Oppenauer C, Lueger-Schuster B, Moser E, Kryspin-Exner I, Bauer $\mathrm{H}$. Altered reward processing in the nucleus accumbens and mesial prefrontal cortex of patients with posttraumatic stress disorder. Neuropsychologia. 2008; 46(11):2836-44. [PMID:18597797]

http://dx.doi.org/10.1016/j.neuropsychologia.2008.05.022

54. Topal NB, Hakyemez B, Erdogan C, Bulut M, Koksal O, Akkose S, Dogan S, Parlak M, Ozguc H, Korfali E. MR imaging in the detection of diffuse axonal injury with mild traumatic brain injury. Neurol Res. 2008;30(9):974-78.

[PMID:18691451]

http://dx.doi.org/10.1179/016164108X323799

55. Lo C, Shifteh K, Gold T, Bello JA, Lipton ML. Diffusion tensor imaging abnormalities in patients with mild traumatic brain injury and neurocognitive impairment. J Comput Assist Tomogr. 2009;33(2):293-97. [PMID:19346863] http://dx.doi.org/10.1097/RCT.0b013e31817579d1

56. Holbrook TL, Galarneau MR, Dye JL, Quinn K, Dougherty AL. Morphine use after combat injury in Iraq and posttraumatic stress disorder. N Engl J Med. 2010;362(2):110-17. [PMID:20071700] http://dx.doi.org/10.1056/NEJMoa0903326

57. Pietrzak RH, Johnson DC, Goldstein MB, Malley JC, Southwick SM. Psychological resilience and postdeployment social support protect against traumatic stress and depressive symptoms in soldiers returning from Operations Enduring Freedom and Iraqi Freedom. Depress Anxiety. 2009;26(8):745-51. [PMID:19306303] http://dx.doi.org/10.1002/da.20558

Submitted for publication December 28, 2011. Accepted in revised form September 10, 2012.

This article and any supplementary material should be cited as follows:

Ruff RL, Riechers RG 2nd, Wang X-F, Piero T, Ruff SS. For veterans with mild traumatic brain injury, improved posttraumatic stress disorder severity and sleep correlated with symptomatic improvement. J Rehabil Res Dev. 2012;49(9):1305-20.

http://dx.doi.org/10.1682/JRRD.2011.12.0251

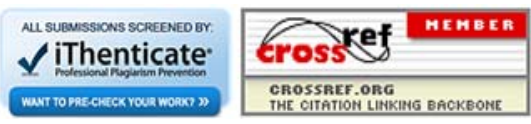

